OPEN ACCESS

Edited by:

Frontiers in Psychiatry,

Frontiers Media SA,

Switzerland

*Correspondence:

Frederico Duarte Garcia

frederico.garciad@gmail.com

Received: 15 April 2019

Accepted: 20 May 2019

Published: 01 July 2019

Citation:

Khoury JM, Couto LFSC,

Santos DdA, Silva VHdO,

Drumond JPS, Silva LLdC,

Malloy-Diniz L, Albuquerque MR, das

Neves MdCL, and Duarte Garcia F (2019) Corrigendum: Bad Choices Make Good Stories: The Impaired Decision-Making Process and Skin Conductance Response in Subjects

With Smartphone Addiction.

Front. Psychiatry 10:397.

doi: 10.3389/fpsyt.2019.00397

\section{Corrigendum: Bad Choices Make Good Stories: The Impaired Decision-Making Process and Skin Conductance Response in Subjects With Smartphone Addiction}

\author{
Julia Machado Khoury 1,2,3, Luiz Filipe Silva Codorino Couto ${ }^{1}$, Douglas de Almeida Santos ${ }^{1}$, \\ Vitor Hugo de Oliveira e Silva', João Pedro Sousa Drumond'2, Letícia Lopes de Carvalho e Silva ${ }^{2}$, \\ Leandro Malloy-Diniz ${ }^{1,3}$, Maicon Rodrigues Albuquerque ${ }^{3,4,5}$, \\ Maila de Castro Lourenço das Neves ${ }^{1,3,5}$ and Frederico Duarte Garcia ${ }^{1,3,5,6 *}$ \\ ${ }^{1}$ Department of Mental Health, Universidade Federal de Minas Gerais-UFMG (Federal University of Minas Gerais), Belo \\ Horizonte, Brazil, ${ }^{2}$ Department of Clinical Medicine, Faculty of Health and Human Ecology, Belo Horizonte, Brazil, \\ ${ }^{3}$ Post-Graduation Program in Molecular Medicine (Pós-Graduação em Medicina Molecular), School of Medicine, Universidade \\ Federal de Minas Gerais-UFMG (Federal University of Minas Gerais), Belo Horizonte, Brazil, ${ }^{4}$ Department of Sports, \\ Universidade Federal de Minas Gerais-UFMG (Federal University of Minas Gerais), Belo Horizonte, Brazil, 5 INCT of \\ Molecular Medicine, Universidade Federal de Minas Gerais-UFMG (Federal University of Minas Gerais), Belo Horizonte, \\ Brazil, 6 Unité Inserm U1073, Rouen, France
}

Keywords: decision-making, game of dice task, lowa gambling test, skin conductance, smartphone addiction, somatic markers

\section{A Corrigendum on}

Bad Choices Make Good Stories: The Impaired Decision-Making Process and Skin Conductance Response in Subjects With Smartphone Addiction by Khoury JM, Couto LFSC, Santos DdA, e Silva VHO, Drumond JPS, Silva LLdC, Malloy-Diniz L, Albuquerque MR, das Neves MCL and Duarte Garcia F (2019). Front. Psychiatry 10:73. doi: 10.3389/ fpsyt.2019.00073

In the published article, there was an error in affiliations $1,3,4$, and 5 .

As required by our institution, "UFMG" should appear in the author affiliations. Instead of the following: "Department of Mental Health, Federal University of Minas Gerais, Belo Horizonte, Brazil," "Post-Graduation Program in Molecular Medicine, School of Medicine, Federal University of Minas Gerais, Belo Horizonte, Brazil," "Department of Sports, Federal University of Minas Gerais, Belo Horizonte, Brazil," and "5INCT of Molecular Medicine, Federal University of Minas Gerais, Belo Horizonte, Brazil" the affiliations should read as follows: "Department of Mental 
Health, Universidade Federal de Minas Gerais-UFMG (Federal University of Minas Gerais), Belo Horizonte, Brazil," “3PostGraduation Program in Molecular Medicine (Pós-Graduação em Medicina Molecular), School of Medicine, Universidade Federal de Minas Gerais-UFMG (Federal University of Minas Gerais), Belo Horizonte, Brazil," "Department of Sports, Universidade Federal de Minas Gerais-UFMG (Federal University of Minas Gerais), Belo Horizonte, Brazil," and "5INCT of Molecular Medicine, Universidade Federal de Minas Gerais-UFMG (Federal University of Minas Gerais), Belo Horizonte, Brazil."
The authors apologize for this error and state that this does not change the scientific conclusions of the article in any way. The original article has been updated.

Copyright (c) 2019 Khoury, Couto, Santos, Silva, Drumond, Silva, Malloy-Diniz, Albuquerque, das Neves, and Duarte Garcia. This is an open-access article distributed under the terms of the Creative Commons Attribution License (CC BY). The use, distribution or reproduction in other forums is permitted, provided the original author(s) and the copyright owner(s) are credited and that the original publication in this journal is cited, in accordance with accepted academic practice. No use, distribution or reproduction is permitted which does not comply with these terms 